\title{
A scientific note on detection of honeybee viruses in the darkling beetle (Alphitobius diaperinus, Coleoptera: Tenebrionidae), a new pest in Apis cerana cerana colonies
}

\author{
Zhiguo $\mathrm{LI}^{1}$, Shaokang $\mathrm{HuANG}^{1}$, Wei-fone $\mathrm{HuANG}^{1}$, Haiyang $\mathrm{GenG}^{1}$, Yazhou ZHAO ${ }^{2}$, Meng $\mathrm{LI}^{1}$, Yanping $\mathrm{CHEN}^{3}$, \\ Songkun $\mathrm{Su}^{1}$ \\ ${ }^{1}$ College of Bee Science, Fujian Agriculture and Forestry University, Fuzhou 350002, China \\ ${ }^{2}$ Institute of Apiculture, Chinese Academy of Agricultural Sciences, Beijing 100093, China \\ ${ }^{3}$ USDA-ARS, Bee Research Laboratory, Beltsville, MD 20705, USA
}

Received 30 September 2015 - Revised 27 December 2015 - Accepted 12 January 2016

viruses / Apis cerana / Alphitobius diaperinus / honeybees

The darkling beetle, also known as the lesser mealworm (Alphitobius diaperinus Panzer, Coleoptera: Tenebrionidae), exhibits a cosmopolitan distribution in poultry houses and piggeries (McAllister et al. 1995). A. diaperinus originates from sub-Saharan Africa, and this species has adapted to moist and warm poultry facilities (Geden and Hogsette 1994). A. diaperinus is a nocturnal omnivore considered as a serious pest of poultry facilities; low light environments, such as poultry houses and piggeries, provide an optimum habitat for A. diaperinus (Esquivel et al. 2012). Larvae and adults can damage poultry houses by tunnelling into insulation materials (Esquivel et al. 2012). The lesser mealworm beetle can also act as a reservoir of poultry pathogens, including viruses, bacteria and fungi (McAllister et al. 1995; Esquivel et al. 2012). Our study described the lesser mealworm inhabiting honeybee (Apis cerana cerana) hives.

A. diaperinus beetles were first found in our experimental apiary during our hive inspection in daytime twice a week. We further surveyed two more apiaries to further confirm that A. diaperinus is a new pest in $A$. $c$.

Electronic supplementary material The online version of this article (doi:10.1007/s13592-016-0430-1) contains supplementary material, which is available to authorized users.

Corresponding author: S. Su, susongkun@zju.edu.cn Manuscript editor: Stan Schneider cerana colonies. The three honeybee (A. c. cerana) apiaries were located in Fuzhou, Fujian Province, Southeast China (latitude $\mathrm{N} 26^{\circ} 08^{\prime}$, longitude E119 $\left.28^{\prime}\right)$. The honeybees were kept in a four-frame hive with Langstroth frames, and all of the colonies examined in the study were queenright and strong in population. A. diaperinus beetles were seen inhabiting the surface area of the solid bottom boards of hives, the cracks and joints of the bottom boards and the frames (top and bottom bars) of combs. Two to eighteen beetles were found in each inhabited hive. The number of beetles inhabiting the three different apiaries significantly differed, as revealed by nonparametric Kruskal-Wallis test $(P<0.05)$. The beetle parasitism rates in the three different apiaries were $34.5 \%(10 / 29), 30.8 \%(4 / 13)$ and $36.7 \%$ (11/30), respectively. The beetle larvae were also observed in the cracks and crevices of the bottom boards of the hives. Some beetles were resting inside the empty cells of the combs. Other beetles were distributed in clusters in the shadow of the hives. They tended to avoid light and rested underneath the fallen hive debris when the inner cover of the hive was opened. However, beetle eggs were not observed in the hives.

The adult lesser mealworms collected from A. $c$. cerana colonies were further used to examine whether they can act as reservoirs of common honeybee viruses. The adult lesser mealworms were individually surfacesterilised with $10 \%$ sodium hypochlorite for $10 \mathrm{~min}$ and then used for RNA extraction with TRIzol (Invitrogen) in accordance with the manufacturer's instructions. 
Total RNA $(3 \mu \mathrm{g})$ was reverse-transcribed to cDNA by using the Primescript ${ }^{\mathrm{TM}}$ first-strand cDNA synthesis kit (Takara). The synthesised cDNA was subjected to PCR amplification of seven common honeybee viruses (online resource Table S1). The PCR was performed with the same amplification program as in our previous study (Li et al. 2014). The expected PCR products were directly sequenced to further confirm the RT-PCR based results. The sequences obtained in this study were submitted to GenBank, and the accession numbers were received (online resource Figure S1). The virus sequences obtained from the beetles and from the honeybees (Apis mellifera) retrieved from GenBank were phylogenetically analysed in MEGA6 software (Tamura et al. 2013). A tagged RT-PCR was employed to detect the negative-stranded transcripts of Black queen cell virus (BQCV) and Israeli acute paralysis virus (IAPV) in adult lesser mealworms to investigate whether these honeybee viruses can replicate in the adult lesser mealworms. The total RNA and the tagged primers used in previous studies were used to synthesise the cDNA of BQCV and IAPV, respectively (Kukielka et al. 2008; Li et al. 2014). The cDNA was then cleaned with a MinElute ${ }^{\circledR}$ reaction cleanup kit (Qiagen) to remove short oligonucleotides and inorganic ions and to improve the specificity of PCR. The purified cDNA was then used to detect the replication intermediates of BQCV and IAPV; PCR was performed in accordance with previously described methods by using a tag primer (Yue and Genersch 2005) as sense primers and virusspecific primers as antisense primers (Kukielka et al. 2008; Li et al. 2014).

BQCV and IAPV could be detected in the adult lesser mealworms (Figure 1a). This result suggested that the beetles were infected with BQCV and IAPV. Of the detected beetles $(n=30), 36 \%$ were free of BQCV and IAPV, $7 \%$ were infected with BQCV and IAPV, $10 \%$ were detected with BQCV and $60 \%$ were detected with IAPV. The negative-stranded transcripts of BQCV and IAPV were found in the adult lesser mealworms. This result indicated that BQCV and IAPV could replicate in the beetles (Figure 1b). Therefore, the beetles could act as possible reservoirs of BQCV and IAPV. Furthermore, a host shift from A. mellifera to the beetle may exist in BQCV and IAPV. Compared with the viral sequences from A. mellifera, evolutionary analyses showed that the partial sequences of the capsid protein of BQCV from $A$. diaperinus clustered together and formed a distinct branch (online resource Figure S1). The partial sequences of the helicase protein of IAPV also clustered

\section{a}

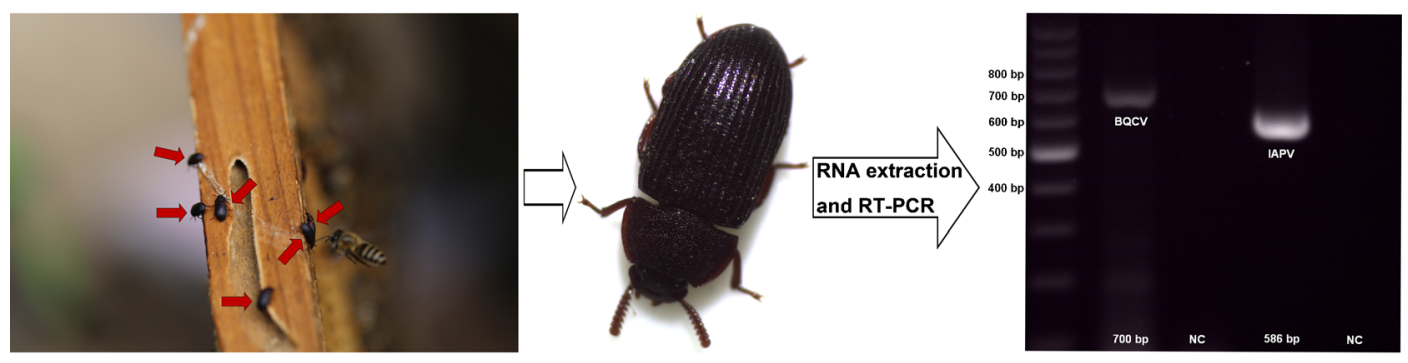

b
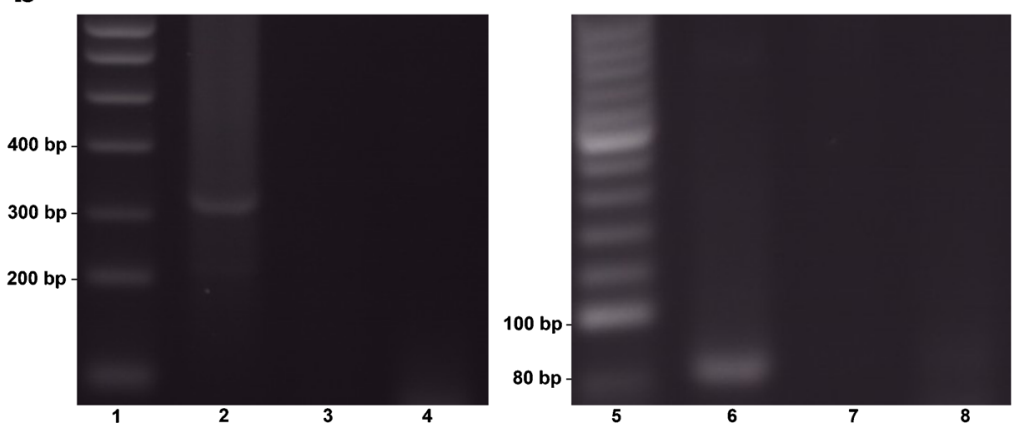

Figure 1. Detection of BQCV (700 bp) and IAPV (586 bp) in A. diaperinus, and the red arrow indicates the adult beetles observed in top bar of the comb from an A. c. cerana hive. $N C$ negative control (no template) (a). Detection of negative-strand RNAs of BQCV (305 bp, Lane 2) and IAPV (84 bp, Lane 6) in A. diaperinus (b). Lane 1 and 5: DNA Ladder; Lane 3 and 7: negative control (no tag primer); Lane 4 and 8: negative control (no template). 
together but separated from the viral sequences from A. mellifera (online resource Figure $\mathrm{S} 1$ ). The sequences of $\mathrm{BQCV}$ from $A$. diaperinus ranged in identity from 99.55 to $100 \%$; these sequences exhibited 91.24 to $99.55 \%$ sequence identity with those in A. mellifera. The sequences of IAPV from $A$. diaperinus showed $100 \%$ identity and exhibited 88.69 to $99.04 \%$ sequence identity with those in A. mellifera .

A. diaperinus beetles show distinct morphological characteristics from small hive beetle (Aethina tumida, SHB) that originates from sub-Saharan Africa as well (Neumann et al. 2013). Honeybee viruses, such as Deformed wing virus (DWV), can infect and replicate in small hive beetle inhabiting A. mellifera colonies (Eyer et al. 2009). There are currently no reports that suggest that SHB inhabits A. c. cerana colonies. Similar to SHB, lesser mealworm beetles can act as possible reservoirs of honeybee viruses in A. c. cerana colonies. Finding BQCV and IAPV in the beetle could result from the wide host ranges of the viruses which can be detected in various hosts (Eyer et al. 2009; Li et al. 2014). These results further demonstrate that the darkling beetle, A. diaperinus, is a competent reservoir host of poultry and honeybee pathogens (McAllister et al. 1995; Esquivel et al. 2012). There were fallen cell cappings, mouldy pollen, and even dead bees, brood or adults, that could be found on the bottom board of the hive. The beetles may scavenge these potential food sources on the bottom boards and may therefore consume honeybee viruses contained in the food sources. This study is the first to describe lesser mealworm in A. c. cerana colonies with the adult beetles acting as reservoir hosts of honeybee viruses. However, further research is needed to investigate the molecular mechanism of the host switching in honeybee viruses, and interactions between beetles and A. c. cerana .

\section{ACKNOWLEDGMENTS}

This work was supported by the earmarked fund for Modern Agro-industry Technology Research System (No.CARS-45-KXJ3) and National Natural Science Foundation of China (31340061).
Note scientifique sur la détection de virus d'abeille chez Alphitobius diaperinus (Coleoptera: Tenebrionidae), un nouveau ravageur des colonies d'Apis cerana cerana

Eine wissenschaftliche Notiz über die Entdeckung von Honigbienenviren beim Schwarzkäfer (Alphitobius diaperinus, Coleoptera: Tenebrionidae), einem neuen Parasiten in Apis cerana cerana

\section{REFERENCES}

Esquivel, J., Crippen, T., Ward, L. (2012) Improved visualization of Alphitobius diaperinus (Panzer) (Coleoptera: Tenebrionidae)_-Part I: Morphological features for sex determination of multiple stadia. Psyche J. Entom. $2012,1-7$

Eyer, M., Chen, Y.P., Schäfer, M.O., Pettis, J., Neumann, P. (2009) Small hive beetle, Aethina tumida, as a potential biological vector of honeybee viruses. Apidologie 40(4), 419-428

Geden, C.J., Hogsette, J. (1994) Research and extension needs for integrated pest management for arthropods of veterinary importance. In: Proceedings of a Workshop in Lincoln. Nebraska, $1-328$

Kukielka, D., Esperón, F., Higes, M., Sánchez-Vizcaíno, J.M. (2008) A sensitive one-step real-time RT-PCR method for detection of deformed wing virus and black queen cell virus in honeybee Apis mellifera . J. Virol. Methods 147 (2), 275281

Li, Z., Su, S., Hamilton, M., Yan, L., Chen, Y. (2014) The ability to cause infection in a pathogenic fungus uncovers a new biological feature of honey bee viruses. J. Invertebr. Pathol. 120, $18-22$

McAllister, J., Steelman, C., Newberry, L., Skeeles, J. (1995) Isolation of infectious bursal disease virus from the lesser mealworm, Alphitobius diaperinus (Panzer). Poult. Sci. 74 (1), 45-49

Neumann, P., Evans, J.D., Pettis, J.S., Pirk, C.W., Schäfer, M.O., Tanner, G., Ellis, J.D. (2013) Standard methods for small hive beetle research. J. Apic. Res. 52 (4), 1-32

Tamura, K., Stecher, G., Peterson, D., Filipski, A., Kumar, S. (2013) MEGA6: molecular evolutionary genetics analysis version 6.0. Mol. Biol. Evol. 30(12), 27252729

Yue, C., Genersch, E. (2005) RT-PCR analysis of Deformed wing virus in honeybees (Apis mellifera) and mites (Varroa destructor). J. Gen. Virol. 86(12), 3419-3424 